EESTI NSV TEADUSTE AKADEEMIA TOIMETISED. 21. KOIDE

KEEMIA * GEOLOOGIA. 1972, NR. 4

ИЗВЕСТИЯ АКАДЕМИИ НАУК ЭСТОНСКОЙ ССР. ТОМ 21

ХИМИЯ * ГЕОЛОГИЯ. 1972, № 4

\title{
ФАЦИАЛЬНЫЕ КОМПЛЕКСЫ ДАУНТОНСКИХ ОСТРАКОД ПРИБАЛТИКИ
}

В даунтонском веке на территории Прибалтики существовал залив позднесилурийского моря, который по некоторым представлениям был разделен полуостровом в районе Лиепая-Салдусского поднятия (Гайлите и др., 1967; Поливко, Ульст, 1969). В этом заливе происходило накопление глинисто-карбонатных отложений: глин, мергелей, известковых илов, часто детритовых или органогенно-обломочных. В прибрежных частях залива происходило накопление преимущественно карбонатных осадков, в то время как в центральных частях осаждались глинистокарбонатные илы.

К даунтонским отложениям Прибалтики приурочены сообщества остракод, в которых преобладают представители четырех таксон - семейств Beyrichiidae, Kloedeniidae, Primitiopsidae и отряда Podocopida, имеющие резко отличные морфологические признаки раковин. Бейрихииды характеризуются развитием крупных, массивных, грубо скульптированных раковин, клоэденииды - развитием крупных, массивных, но в меньшей степени расчлененных бороздами створок, подокопиды - развитием небольших, гладких раковин. Примитиопсиды отличаются значительным морфологическим разнообразием и имеют как гладкие, толстостенные и массивные (амигралеллы, поленовулы), так и пористые, ячеистые и ребристые, тонкостенные раковины (примитиопсисы, клавофабеллы, вензавеллы, оркофабеллы).

С целью выяснения некоторых аспектов экологии этих остракод изучались соотношения разных их групп в составе ассоциаций в зависи-

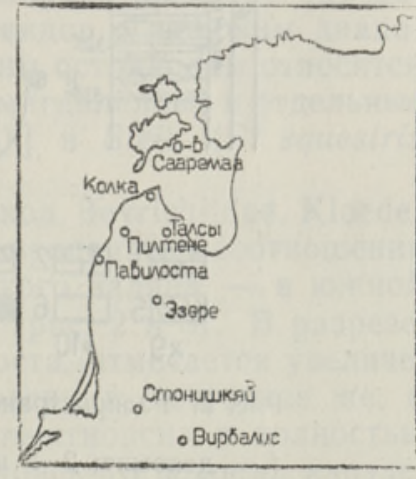

Рис. 1. Схема распространения опробованных разрезов даунтонских отложений. мости от литологического состава вмещающих пород, точнее от преобладания в них глинистой или карбонатной составляющих. Подобный анализ был проведен в разрезе скв. Колка № 4, расположенной в северной части Курземе (Западная Латвия) (рис. 1 и 2). В нижней части $(305-335$ м) даунтонских отложений в разрезе этой скважины залегают преимущественно глинистые породы - глинистые мергели и глины с линзовидными и комковатыми включениями известняков, сменяющиеся кверху (245-305 м) переслаиванием глинистых мергелей и известняков. 
Во время образования глинистых мергелей с комковатыми включениями известняков, очевидно, существовали благоприятные для расцвета остракодовой фауны условия. Об этом свидетельствует максимальное количество остракод в образцах, отобранных из этих отложений, и значительное таксономическое разнообразие их. Раннедаунтонские сообщества остракод отличаются преобладанием крупных необейрихий [Neobeyrichia buchiana (Jones), N. alia Gail., N. incerta Gail.], хемсиэлл [Hemsiella dalmaniana (Jones), H. margaritae Gail.] наравне с крупными,

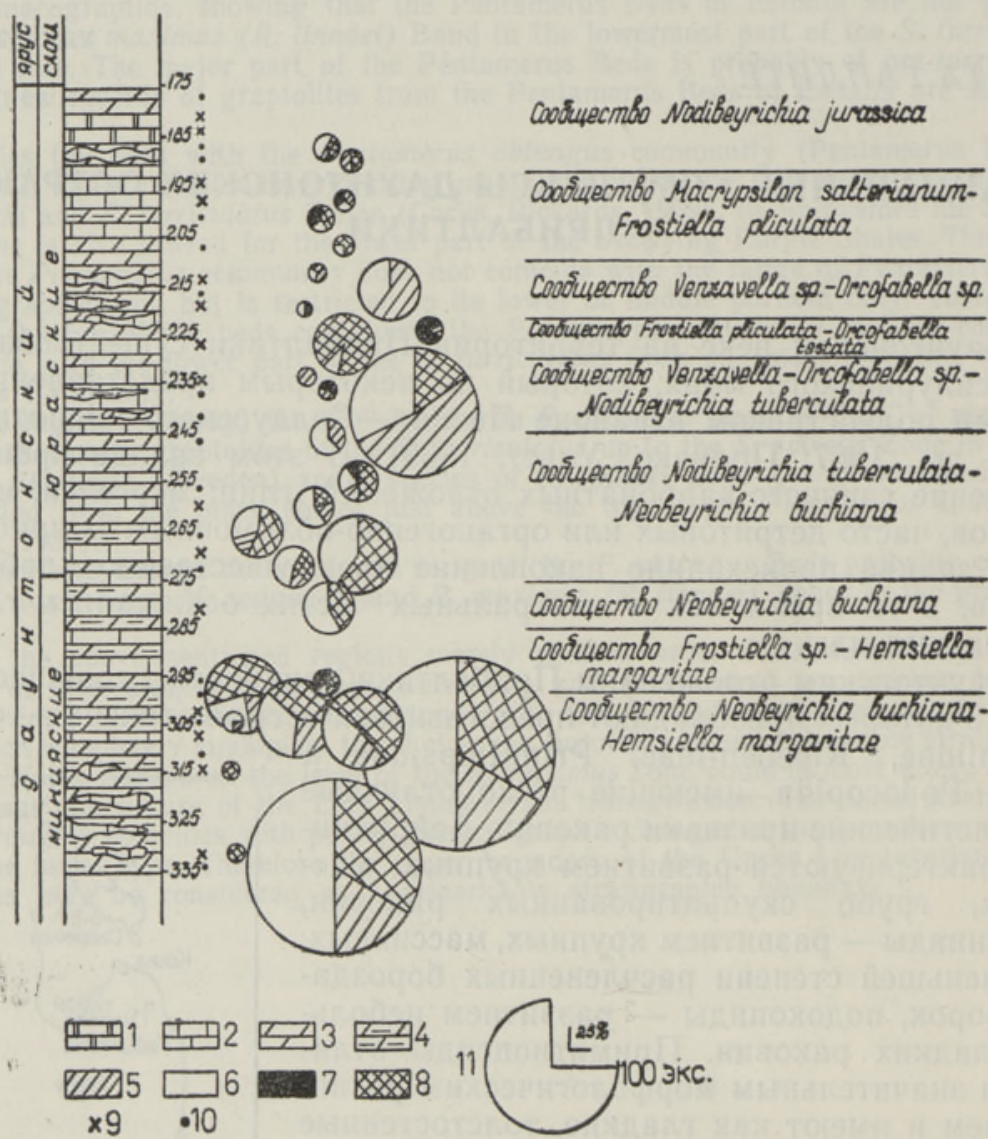

Рис. 2. Распространение сообществ остракод в даунтонских отложениях скв. Колка № 4.

1 - доломит; 2 - известняк; 3 - мергель; 4 - мергель глинистый; 5 - Prımitiopsidae; 6 - Beyrichiidae; 7 - Kloedeniidae; 8 - Podocopida: 9,10 - места отбора проб из мергелей (9) и известняков (10); 11 - величина круга, соответствующая 100 экз. и $100 \%$ остракод.

гладкими примитиопсидами (амигдалеллами, поленовулами). Сказанное касается только комплексов остракод из глинистых разностей пород; в пробах, отобранных из линзовидных и комковатых включений известняков, количество остракод, представленных только гладкими подокопидами, резко сокращается. Несколько позднее, в период формирования толщи переслаивания глинистых мергелей и известняков, наблюдается бо́льшая приспособляемость остракод к условиям, существовавшим во время образования глинистых и карбонатных разностей пород: как те, 
так и другие, заключают крупные нео- и нодибейрихии [Neobeyrichia buchiana (Jones), N. alia Gail., N. incerta Gail., Nodibeyrichia tuberculata (Klöden)], гладкие примитиопсиды [Amygdalella subclusa (Jones), A. nasuta Mart.], подокопиды и редкие клоэденииды. Можно отметить лишь некоторое увеличение содержания подокопид в прослоях известняка. В целом же условия среды во время существования названных сообществ, по-видимому, заметно не изменялись.

В верхней части разреза даунтонских отложений скв. Колка № 4 $(175-245$ м) увеличивается значение известняков, встречающихся в виде прослоев, линз и комков. Параллельно происходят заметные изменения в составе остракодовых сообществ, что проявляется в увеличении количества видов и экземпляров клоэдениид, в появлении наряду с гладкими примитиопсидами (амигдалеллами) ячеистых и ребристых оркофабелл и вензавелл. Сокращается содержание крупных бейрихиид, представленных здесь в основном бугристыми и бугорчатыми Nodibeyrichia tuberculata (Klöden), N. gedanensis Mart. и N. jurassica Gail. Резко увеличивается количество экземпляров вида Macrypsilon salterianum (Jones). Однако общее количество родов, видов и экземпляров остракод сокращается.

Выявленные два основных комплекса остракод, по-видимому, связаны с регрессивным характером даунтонского водоема и отражают смену форм, приспособленных к жизни в относительно более глубоководных условиях с нормальной соленостью, формами, обитавшими в условиях мелководья. К первым относятся крупные необейрихии и хемсиэллы, т. е. остракоды, преобладающие в глинисто-карбонатных отложениях нижней части разреза и являющиеся стеногалинными формами, предпочитавшими селиться на глинистых грунтах. Эвригалинными остракодами, обитавшими в условиях крайнего мелководья и приспособленными к жизни на известковых грунтах, являются ячеистые и ребристые примитиопсиды (оркофабеллы и вензавеллы), бугорчатые нодибейрихии, клоэдении и фростиэллы. Наряду с остракодами, обитавшими в каких-либо определенных условиях, выявился ряд эврибионтных видов с широким диапазоном условий обитания. В первую очередь к этим остракодам относятся подокопиды, а также гладкие примитиопсиды (амигдалеллы) и отдельные виды родов Hemsiella [H. dalmaniana (Jones)] и Sleia (S. equestris Mart.).

Анализ площадного распространения остракод Beyrichiidae, Kloedeniidae, Primitiopsidae и Podocopida дал равные процентные соотношения этих четырех групп в северной части даунтонского залива - в южной части о. Сааремаа, в районе Колка и Пилтене (рис. 2 и 3). В разрезе, расположенной несколько западнее скв. Павилоста, отмечается увеличение содержания бейрихиид и сокращение клоэдениид, восточнее же, в разрезе скв. Талсы, возрастает содержание примитиопсид и полностью отсутствуют клоэденииды. В южной части даунтонского водоема клоэденииды также содержатся в меньших количествах (скважины Әзере и Вирбалис) или отсутствуют совсем (скв. Стонишкяй). Одновременно там происходит увеличение доли бейрихиид и подокопид (скв. Эзере и Стонишкяй), бейрихиид и примитиопсид (скв. Вирбалис).

Наибольшее разнообразие родового состава бейрихиид приурочено к разрезам даунтона в южной части о. Саарема и в Западной Латвии (Пилтене), где присутствуют роды Retisacculus, Sleia, Hemsiella, Juviella, Macrypsilon, Neobeyrichia, Nodibeyrichia, Plicibeyrichia, Calcaribeyrichia (рис.4). Остракоды двух последних родов, судя по морфологическим признакам раковин - развитию крупных шипов на створках, способствующих удержанию раковины на поверхности грунта, приспособлены

5 ENSV TA Toimetised $\mathrm{K} * \mathrm{G}-41972$ 

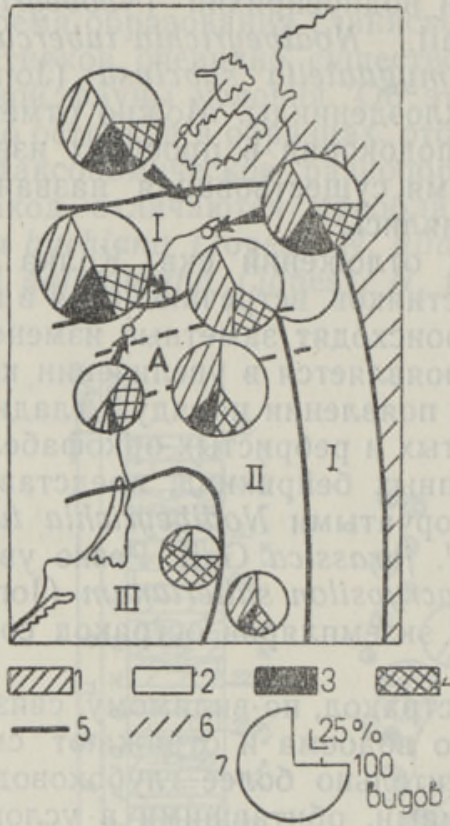

Рис. 3. Сообщества остракод в даунтонских отложениях Прибалтики

1 - Primitiopsidae; 2 - Beyrichidae; 3 - Kloedeniidae; 4 Podocopida; 5 - границы pacпространения зон прибрежного (I), мелководного (II) и относительно глубоководного (III) комплексов остракод; 6 - область сноса; 7 - величина круга, соответствующая 100 видам и $100 \%$ остракод; $A$ - Лиепая-Салдусский вал.

к жизни вблизи береговой линии. В даунтонских отложениях Сааремаа и разреза Пилтене значительно увеличивается содержание клоэдениид из родов Kloedenia и Frostiella, что также свидетельствует о мелководности морского бассейна. Восточнее и западнее этих разрезов, в даунтонских разрезах скважин Талсы и Павилоста, присутствуют, кроме единичных представителей родов Frostiella и Calcaribeyrichia, главным образом более «глубоководные» роды остракод - Neobeyrichia, Nodibeyrichia, Hem. siella. Сказанное относится к южной части даунтонского водоема. Лишь в разрезе даунтона скв. Эзере представлены роды Kloedenia и Frostiella, не распространенные в более южных и глубоководных частях залива (скв. Стонишкяй). В последних набор родов бейрихиид невелик: он содержит остракоды родов Hemsiella, Neobeyrichia, Sleia и одиночные нодибейрихин.

Аналогичные результаты получены при анализе остракод Primitiopsidae (рис. 5); наибольшее количество родов примитиопсид (роды Primitiopsis, Clavofabella, Orcofabella, Venzavella, Amygdalella, Scipionis, Leiocyamus) встречено в даунтонских отложениях южной части о. Саaре- 
маа и в разрезе скв. Пилтене, несколько меньшее количество - в разрезах Колка № 4 и Талсы в северной части даунтонского залива. В отложениях южной части даунтонского залива увеличивается процентное содержание остракод родов Amygdalella, Scipionis, Polenovula. В крайней юго-западной части водоема, в области распространения глинисто-карбонатных пород, встречены только гладкие, более «глубоководные» примитиопсиды родов Amygdalella и Scipionis.

Таким образом, сравнительный анализ сообществ остракод, захороненных непосредственно у береговой зоны даунтонского залива (южная часть современного о. Сааремаа) и в некотором отдалении от нее (район скважин Вирбалис и Стонишкяй), подтвердил вывод, сделанный при анализе вертикальной смены сообществ остракод в разрезе даунтона скв. Колка. Согласно ему к проживанию в относительно глубоководных условиях приспособлены крупные бейрихииды - необейрихии и хемсиэллы, которые предпочитали селиться на глинистых грунтах. K усливиям крайне мелководным, частс сопровождающимся повышением солености воды, о чем свидетельствует доломитизация пород, были приспособлены украшенные шипами и бугорками калькарибейрихии, нодибейрихии, клоэденииды, ячеистые и ребристые примитиопсиды - оркофабеллы и вензавеллы, которые селились преимущественно на известковых грунтах. Наряду с этими двумя группами остракод существовали эврибионтные виды и роды, которые как по разрезу, так и по площади распространены весьма широко, независнмо от вещественного состава пород и фациальных условий. К эврибионтным острако дам относятся в первую очередь представители подокопид и гладкие примитиопсиды - амигдалеллы.

Беспорядочная ориентировка раковин свидетельствует об отсутствии течений, в то время как нахождение главным образом разрозненных створок остракод (за исключением отдельных групп, например амигдалелл и подокопид, представленных часто целыми раковинами), лежащих на грунте то наружной, то внутренней стороной кверху, указывает на длительное пребывание
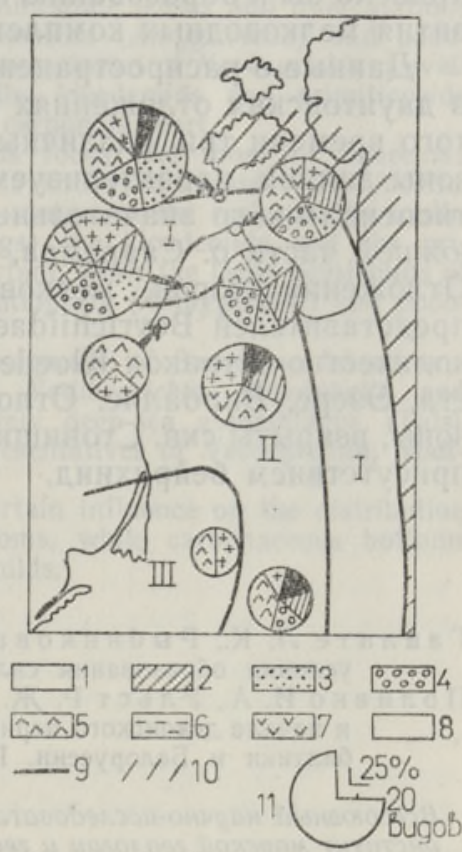

Рис. 5. Сообщества примитиопсид в даунтонских отложениях Прибалтики.

1 - Primitiopsis; 2 - Clavofabella; 3 - Orcofabella; 4 Venzavella; 5 - Amygdalella; 6 - Scipionis; 7 - Polenovula; 8 - Leiocyamus; 9 - границы зон распространения прибрежного (I), мелководного (II) и относительно глубоководного (III) комплексов остракод; 10 - область сноса; 11 - величнна круга, соответствующая 20 видам и $100 \%$ остракод; $A-$ Лиепая-Салдусский вал. раковин перед захоронением в зоне волнового движения.

Развитие чрезвычайно богатого, типичного для самых благоприятных условий комплекса даунтонских остракод в южной части о. Сааремаа свидетельствует о близости береговой линии моря. Сокращение количества представителей отдельных групп остракод сопровождается изменением их видового и родового составов - уменьшением доли «мелководных» остракод в разрезах ряда скважин (Талсы, Павилоста, Эзере, Вирбалис), расположенных близ границ современного распространения даунтона. Это позволяет предположить, что площадь, занятая даунтон- 
ским морем, была гораздо обширнее региона современного развития этих образований, а также связать отсутствие подобных сааремааскому комплексов остракод в других районах с последаунтонской эрозией включающих их пород. Это отсутствие прибрежных комплексов остракод в даунтоне скважин Павилоста, Талсы и Эзере, находящихся у границ современного распространения даунтонских отложений вдоль ЛиепаяСалдусского вала, позволяет предположить, что развитие упомянутого вала проходило в последаунтонское время, ибо вздымание его в даунтоне привело бы к образованию прибрежных условий, благоприятных для развития мелководных комплексов остракод.

Данные о распространении и процентном содержании родов остракод в даунтонских отложениях Прибалтики позволяІот выделить в бассейне того времени три различные по глубине зоны. Отложения прибрежной зоны залива, характеризуемые преимущественно бейрихиидами, примитиопсидами, со значительным содержанием клоэдениид, сохранились в южной части о. Сааремаа, в разрезах скважин Пилтене и Колка № 4. Отложения второй, мелководной зоны, содержащие главным образом представителей Beyrichiidae, Primitiopsidae, Podocopida и минимальное количество остракод Kloedeniidae, вскрыты скважинами Талсы, Павилоста, Эзере, Вирбалис. Отложения третьей, относительно глубоководной зоны, вскрыты скв. Стонишкяй и отличаются преобладанием подокопид и присутствием бейрихиид.

\section{ЛИТ Е Р А Т Р А}

Г айлите Л. К., Рыбникова М. В., Ульст Р. Ж. 1967. Стратиграфия, фауна и условия образования силурийских пород Средней Прибалтики. Рига.

П оли в ко И. А., У льст Р. Ж. 1969. Геологическая обстановка в конце силурийского и начале девонского периодов в Прибалтике. В сб.: Региональная геология Прибалтики и Белоруссии. Рига.

Всесоюзный научно-исследовательский институт морской геологии и геофизики

Поступила в редакцию $15 /$ XII 1971

\section{LILITA GAILITE}

\section{BALTIKUMI DAUNTONI LADEJÄRGU OSTRAKOODIDE FATSIAALSED KOMPLEKSID}

Artiklis analüüsitakse beirihhiidide, kloedeniidide, primitiopsiidide ja podokopiidide esinemissuhteid seoses neid sisaldavate kivimite litoloogilise iseloomuga vertikaalses läbilōikes (Kolka-4), ja ka pinnaliselt basseini eri osades paiknevatest puuraukudest saadud materjalide alusel. Näidatakse, et rannalähedases assotsiatsioonis, mis on esindatud peamiselt Saaremaal ja Piltene läbilōikes, domineerivad ostrakoodid sugukonnast Kloedeniidae, beirihhiididest Calcaribeyrichia, Nodibeyrichia, primitiopsiididest aga Orcofabella ia Venzavella vormid. Rannast kaugemal moodustunud madalaveelistes, ja ka suhteliselt sügavamaveelistes setetes (Talsi, Pavilosta, Virbalise ja Stoniškjai läbilöiked) on iseloomulikud suuremōôtmelised beirihhiidid perekondadest Neobeyrichia ja Nodibeyrichia, primitiopsii. didest siledad Amygdalella vormid ja podokopiidide seltsi esindajad. 


\section{LILITA GAILITE}

\section{ENVIRONMENTALLY CONTROLLED ASSEMBLAGES OF DOWNTONIAN OSTRACODES IN THE EAST BALTIC AREA}

Downtonian carbonate rocks of the East Baltic area contain a rich assemblage of ostracodes in which representatives of the families Beyrichiidae, Kloedeniidae, Primitiopsidae and of the order Podocopida are predominant. In the vertical distribution of ostracodes in the Downtonian section of the Kolka-4 core, a certain relationship between the ostracode assemblages and the lithology of the rocks may be observed. In the lower part of the sequence represented by clayey marls with limestone lenses and intercalations large beyrichiids (Neobeyrichia and Hemsiella), primitiopsids (Amygdalella) and podocopids are predominant. Nodibeyrichia tuberculata and large forms of Neobeyrichia prevail in the middle, marly part of the section, whereas the kloedeniids and primitiopsids (Orcofabella, Venzavella) predominate in the upper carbonate part.

In the sections consisting mainly of carbonaceous rocks like those of Saaremaa Island and north-western Latvia, kloedeniids, beyrichiids and primitiopsids (Orcofabella, Venzavella) chiefly occur. With the increase of the clay content in the rocks to the southwest (Ezere, Pavilosta, Virbalis and Stoniškjai borings) the kloedeniids and the primitiopsids Orcofabella and Venzavella become less important, while the large beyrichilds of the genera Neobeyrichia and Nodibeyrichia, smooth primitiopsids (Amygdalella) and podocopids are predominant.

It seems that in the near-shore assemblages (the sequence of Saaremaa Island and in the Piltene core) the kloedeniids, Calcarbeyrichia, Nodibeyrichia, Oriofabella and Venzavella are most important. Off-shore and relatively deep-sea assemblages (Talsi, Pavilosta, Virbalis and Stoniškjai cores) consist of representatives of Neobeyrichia, Nodibeyrichia, Amygdalella and podocopids.

It should be noted that bottom sediments had a certain influence on the distribution of ostracodes: large beyrichiids inhabited clayey bottoms, while carbonaceous bottoms were more appropriate for primitiopsids and kloedeniids. 